\title{
Ranunculaceae endémicas del Perú
}

\author{
Blanca León ${ }^{1,2}$
}

${ }^{1}$ Museo de Historia Natural, Av. Arenales 1256, Aptdo. 14-0434, Lima 14, Perú

2 Plant Resources Center, University of Texas at Austin, Austin TX 78712 EE.UU.

blanca.leon@mail.utexas.edu

\section{Resumen}

La familia Ranunculaceae es reconocida en el Perú por presentar ocho géneros y 50 especies (Brako \& Zarucchi, 1993; Ulloa Ulloa et al., 2004), principalmente hierbas. En este trabajo reconocemos ocho especies endémicas en tres géneros. Un género, Laccopetalum, es endémico del Perú. El género más rico en especies es Ranunculus. Las especies endémicas provienen principalmente de las regiones Páramo y Puna Seca y Húmeda, entre los 3200 hasta los $4800 \mathrm{~m}$ de altitud. Se aplicaron las categorías y criterios de la UICN a seis especies. Aparentemente, cuatro especies endémicas se encuentran representadas dentro del Sistema Nacional de Áreas Naturales Protegidas por el Estado.

Palabras claves: Ranunculaceae, Laccopetalum, Ranunculus, Perú, endemismo, plantas endémicas.

\section{Abstract}

The Ranunculaceae are represented in Peru by eight genera and 50 species (Brako \& Zarucchi, 1993; Ulloa Ulloa et al., 2004), mostly herbs. Here we recognize eight endemic species in three genera. One genus, Laccopetalum, is endemic to Peru. Ranunculus is the genus with the largest number of endemic species. Endemic species are found mainly in Paramo, and Humid and Dry Puna regions, between 3200 and 4800 m elevation. We applied IUCN categories and criteria to six species. Apparently, four species have been recorded within Peru's protected areas system.

Keywords: Ranunculaceae, Laccopetalum, Ranunculus, Peru, endemism, endemic plants.

\section{Krapfia macropetala (DC.) M. Tamura}

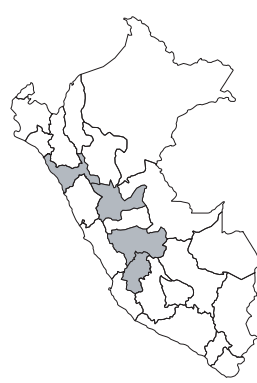

Publicación: Acta Phytotax. Geobot. 44(1):27 1997.

Colección tipo: H. Ruiz \& J. Pavón s.n.

Herbarios: BM, MO.

Nombre común: Desconocido.

Registro departamental: HU, JU, HV, LL. Regiones Ecológicas: PAR; 3200—4300 $\mathrm{m}$.

SINANPE: PNRA

Herbarios peruanos: USM (3).

Observaciones: Este taxón fue considerado por Brako \& Zarucchi (1993) como un endemismo en Ranunculus. No ha sido posible evaluarlo, ni asignarle una categoría.

\section{Laccopetalum giganteum (Wedd.) Ulbr.}

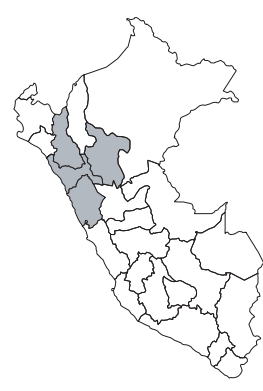

\section{EN, B1ab(iii)}

Publicación: Bot. Jahrb. Syst. 37: 404408. 1906.

Colección tipo: A. Raimondi s.n.

Herbarios: P; USM!.

Nombre común: Pacra pacra.

Registro departamental: AN, CA, LL, SM. Regiones Ecológicas: PSH, PAR, AA; 4000-5300 m.

SINANPE: PNRA

Herbarios peruanos: CPUN (1), HAO (1), HUT (5), USM (holotipo-fr+4).
Observaciones: Esta especie herbácea es una de las más vistosas de la flora de la jalca y la única representante de este género endémico. Raimondi la recolectó en La Libertad y no en Cajamarca, como aparece en la etiqueta original. Weberbauer (1945) la cita de la jalca entre Cajamarca y Hualgayoc, pero, al parecer, esta localidad ha sido destruida. Sus poblaciones están naturalmente fragmentadas. Weberbauer (1945) comentó su rareza en la Cordillera de Pelagatos y la probable especificidad a rocas calcáreas, pero no hay datos que corroboren esta observación. Amenaza principal es la extracción de plantas enteras, para ser comercializadas, por atribuírsele propiedades medicinales y afrodisiacas.

\section{Ranunculus clypeatus (Ulbr.) Lourteig}

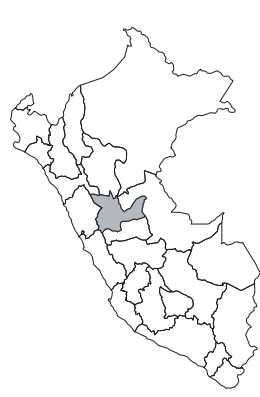

$$
\text { CR, B1ab(iii) }
$$

Publicación: Mem. Soc. Ci. Nat. La Salle 16(44): 166. 1956.

Colección tipo: A. Weberbauer 6728

Herbarios: F, GH; MOL!, USM.

Nombre común: Desconocido.

Registro departamental: HU.

Regiones Ecológicas: PSH; 3800—4000 m.

SINANPE: Sin registro.

Herbarios peruanos: MOL (isotipo), USM (isotipo).

Observaciones: Esta hierba perenne se conoce solamente de una localidad, en la sierra de Huánuco. Aparentemente no ha vuelto a ser recolectada desde 1913. La localidad original ha sido escasamente herborizada desde mediados del siglo XX. Amenazas a sus poblaciones podrían estar asociadas a la quema intencional de pajonales. 


\section{Ranunculus gigas Lourteig}

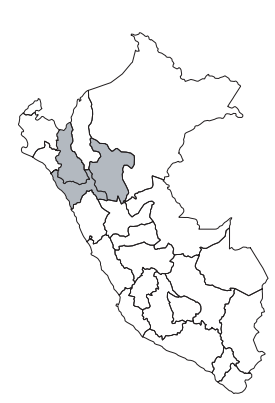

\section{EN, B1ab(iii)}

Publicación: Mem. Soc. Ci. Nat. La Salle 16(44): 166-168. 1956.

Colección tipo: R. Ferreyra 1277

Herbarios: GH, US; MOL!, USM!.

Nombre común: Desconocido.

Registro departamental: CA, LL, SM.

Regiones Ecológicas: PAR; 4100—4800 m.

SINANPE: PNRA

Herbarios peruanos: HUT (2), MOL (isotipo), USM (isotipo+2).

Observaciones: Esta hierba perenne se conoce de varias poblaciones, naturalmente fragmentadas, en el norte del país. Puede hibridar con otra especie endémica, Laccopetalum giganteum, especialmente en el sur, donde contactan sus poblaciones. Los incendios intencionales podrían amenazar sus poblaciones.

\section{Ranunculus lambayequensis T. Duncan \& Sagást.}

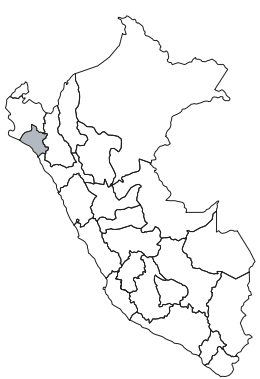

\section{CR, B1ab(iii)}

Publicación: Brittonia 42: 182, f. 1. 1990 Colección tipo: A. Sagástegui A. et al. 12826

Herbarios: F, UC; HUT!

Nombre común: Desconocido.

Registro departamental: LA.

Regiones Ecológicas: PAR; $3300 \mathrm{~m}$.

SINANPE: Sin registro.

Herbarios peruanos: HUT (isotipo).

Observaciones: Esta hierba perenne se conoce de una localidad paramuna, en la cuenca alta del río Leche, en la vertiente occidental, recolectada en 1985. La localidad original está intervenida por aforestación y actividades agrícolas, pastoriles y la construcción de caminos.

\section{Ranunculus luxurians Lourteig}

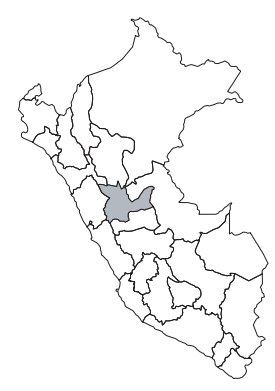

\section{DD}

Publicación: Mem. Soc. Ci. Nat. La Salle 16(43): 77-78. 1956.

Colección tipo: J.F. Macbride 4386

Herbarios: F, GH, MO, NY, US

Nombre común: Desconocido.

Registro departamental: HU.

Regiones Ecológicas: PSH; $3900 \mathrm{~m}$.

SINANPE: Sin registro.

Herbarios peruanos: Ninguno.

Observaciones: Hierba conocida de la cuenca alta del Huallaga, recolectada en 1923. Se desconoce el estado actual de sus poblaciones.

\section{Ranunculus polystachyus Lourteig}

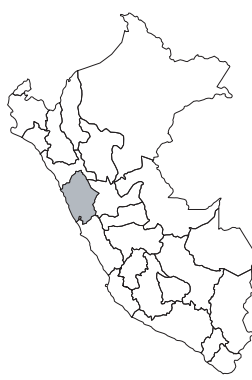

Publicación: Mem. Soc. Ci. Nat. La Salle 16(44): 182-184. 1956.

Colección tipo: P. Marcos 2193

Herbarios: LIL.

Nombre común: Desconocido.

Registro departamental: AN.

Regiones Ecológicas: PSH; $4000 \mathrm{~m}$.

SINANPE: Sin registro.

Herbarios peruanos: HUT (1).

Observaciones: Este taxón fue considerado por Brako \& Zarucchi (1993) como un endemismo; sin embargo, no ha sido posible evaluarlo, ni asignarle una categoría.

\section{Ranunculus weberbaueri (Ulbr.) Lourteig}

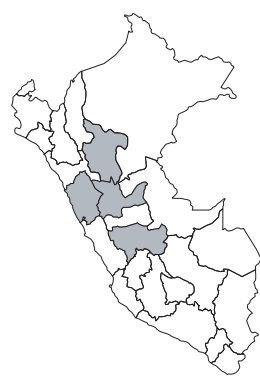

$$
\text { VU, B1ab(iii) }
$$

Publicación: Mem. Soc. Ci. Nat. La Salle 16(44): 168-171. 1956.

Colección tipo: A. Weberbauer 3745

Herbarios: $\mathrm{G}$.

Nombre común: Rima rima.

Registro departamental: AN, HU, JU, SM.

Regiones Ecológicas: BPM; $3400 \mathrm{~m}$.

SINANPE: PNH, PNRA

Herbarios peruanos: USM (1).

Observaciones: Esta especie herbácea es conocida de poblaciones naturalmente aisladas, en ambas vertiente andinas. Incendios intencionales podrían amenazar a sus poblaciones. 